\title{
Analysis of Advantages and Disadvantages of Stability Measures in Permafrost Subgrade
}

\author{
Tang Xinlei ${ }^{1, a,{ }^{*}}$, Mao Xuesong ${ }^{1, b}$, Tang Ke ${ }^{1}$ \\ ${ }^{1}$ School of Chang An University, Shanxi 710064, China. \\ a178605632@qq.com \\ bxuesongxian@aliyun.com
}

Keywords: permafrost, roadbed, control measures, advantages and disadvantages

\begin{abstract}
The stability of permafrost subgrade is an important guarantee for the safe operation of vehicles in permafrost regions. The main factors that affect the stability of roadbed are the change of temperature field of subgrade, surface water on both sides of subgrade and groundwater (frozen water, frozen inter-layer water) and the amount of ice in formation, that is, the strength of protective measures of permafrost hydrothermal influence. The principle of preventing and controlling the stability of permafrost subgrade is to control the temperature field of permafrost subgrade. According to the theory of heat transfer, controlling the radiation, regulating convection and regulating and controlling can effectively control the subgrade temperature field. Board, set the insulation layer, buried hot rod, set the ventilation pipe, riprap embankment, variable thermal conductivity coefficient of materials, insulation materials and other measures. At this stage, there are many stability measures, but there are few advantages and disadvantages of the measures. This article mainly analyzes three main control measures of installing insulation, embedding hot rods and setting ventilation pipes, and analyzes their working mechanism and compares the advantages and disadvantages for a brief.
\end{abstract}

\section{Set the insulation}

\subsection{Insulation mechanism}

Insulation layer embankment engineering measures is from the heat conduction point of view, but not too much in the case of subgrade, add a layer of insulation in the subgrade (such as EPS board), using its low thermal conductivity to prevent external heat into the lower soil, Reduce the atmospheric heat into the roadbed under the form of a subgrade structure, within a certain period of time (such as design life) to play to protect the frozen soil or to delay the degradation of frozen soil role[1].

The smaller the thermal conductivity of the insulation material, the better its effect. Under the control of the temperature boundary condition of approximate sine wave oscillation in the upper part of the soil layer over one year period, the temperature of the lower soil layer also shows the periodic fluctuation with the depth decreasing gradually and the phase gradually lagging. Therefore, the geothermic profile of permafrost is characterized by the dynamic curve between the envelopes formed by the highest and the lowest depth of each soil layer. The maximum temperature envelope is equal to the freezing temperature (usually $0^{\circ} \mathrm{C}$ ), and the depth is Permafrost location. When the insulation layer is not laid, the envelope of the highest and lowest temperature usually has a relatively smooth continuous curve. ${ }^{[2]}$ If the external solar radiation, temperature field, moisture field and stress field remain unchanged after laying the thermal insulation layer, according to the principle of heat conduction, because of the great difference (about 40 times) between the thermal conductivity of thermal insulation material and the thermal conductivity of subgrade soil, a large temperature difference will be formed in the upper and lower insulation layer. This decides the decrease of the annual amplitude of soil temperature in the lower part of the thermal insulation layer, that is, the range between the highest temperature and the lowest temperature. In this case, the envelope of the highest temperature intersects the depth axis at a relatively high depth, that is, the upper limit of the permafrost is raised, which is the rationale for insulation measures to protect 
permafrost.

\section{2 advantages and disadvantages of the insulation}

\section{advantage:}

1) During the hot season, it can effectively prevent the outside hot air from entering the embankment and avoid the degradation of permafrost.

2) low cost.

3) Construction is simple.

\section{Disadvantages:}

1) In the low temperature season, the temperature inside the embankment can not be dispersed .

2) When the permafrost zone is a high-temperature permafrost zone, it is not conducive to the storage of roadbed cold energy.

\section{Set the hot rod}

\section{1 hot rod mechanism}

Hot rod is an important measure to control the permafrost roadbed disease. Hot rod is a two-phase liquid-vapor convection heat transfer device. When the temperature difference exists, the internal material is driven by the two-phase flow of gas and liquid circulation. The endothermic effect of the evaporation section transfers the heat of the soil around the hot rod to the ground or the earth's surface, reducing the temperature of the surrounding soil and increasing the cold storage of the soil around it. The hot rod consists of a sealed metal shell and the internal filling material. The lower part of the tube buried in soil, known as the evaporation section; the upper part of the tube is equipped with cooling fins, called the condensation section and placed in the atmosphere. Its working principle: When the evaporation section temperature is higher than the temperature set by the surrounding soil, the liquid material in the evaporation section absorbs the heat of the surrounding soil and evaporates to form a vapor. Under the effect of pressure difference, the vapor rises to the condensation section along the tube, comes into contact with the condensation tube wall, and emits heat to form a liquid. Under the action of gravity, the liquid material re-absorbs heat and evaporates along the wall of the tube back to the evaporation section. Reciprocating cycle, the soil will continue to send the heat to the atmosphere, thereby reducing the soil temperature. ${ }^{[3]}$ When the temperature of the surrounding soil drops below the temperature set in the condensing section, the liquid material in the hot rod stops evaporating and absorbing heat, and the hot rod will stop working. Hot rods have a one-way thermal conductivity in terms of heat transfer, which transfers heat from the foundation into the atmosphere and does not transfer the heat from the atmosphere down to the foundation. Due to the characteristics of the hot rod, the permafrost layer thickens and its strength increases, thus reducing the subsidence of the permafrost subgrade.

\section{2 advantages and disadvantages of the hot rod}

\section{advantage:}

1) When the subgrade temperature is higher than the working temperature of the hot rod, it is beneficial to lower the temperature of the subgrade under the working of the hot rod.

2) The working principle is easy to understand.

3) Buried is simple and easy to construct.

\section{Disadvantages:}

1) When hot rod layout single root upright, the impact is smaller.

2) It is easy to produce uneven temperature field.

3) The cost is too high. 


\section{Set the ventilation pipe}

\section{1 ventilation pipe mechanism}

According to the flow of air in the tube power, air flow in the tube can be divided into forced convection and natural convection. Forced convection is the movement of an external force that forces the fluid relative to the wall. When the air passes through the duct at a certain initial velocity, the air flow is under a certain pressure and the flow of air through the duct is considered to be one forced convection. Natural convection is caused by the buoyant force due to the difference in density between the cold and hot parts of the fluid. Air flow through the wall when the exchange between the heat transfer process is called convection heat transfer. This process includes both fluid convection convection effect, and the heat transfer between the fluid molecules. It reflects the combined effect of thermal conductivity and convection. Natural convection mechanism: When the air temperature is lower than the air temperature in the ventilation pipe, the air temperature in the ventilation pipe is high, and the density is small. Under the action of buoyancy, natural convection is generated to reduce or maintain the temperature of the roadbed. ${ }^{[4]}$ For the Qingshuihe pilot section of Qinghai-Tibet Railway, the tightness of the concrete pipe joint is poor and the filler is coarse grained soil. When in the melting state, the roadbed body is a solid and a gas two-phase body, so the air flows in the roadbed body and the hot air rises, heat exchange method for the natural convection. Forced convection mechanism: For forced convection, different aspect ratio ventilation ducts are not the same. As the air flow in the pipe wall by the roughness, Reynolds number and the impact of elbow, the wind pressure will be reduced along the way. In order to ensure that the air passes through the vent pipe at a certain initial velocity, the initial air pressure of the air flow must be greater than the air pressure lost when the air flow passes through the vent pipe. Laminar flow and turbulence due to the different physical mechanisms, reflecting different laws of heat transfer. When laminar flow, the heat transfer along the normal direction of the wall depends on the thermal conductivity. ${ }^{[5]}$ When the turbulent flow is flowing, a thin layer closest to the wall has the laminar flow property. In addition to the thin layer, the heat transfer depends on the thermal conduction mechanism, flow disturbance convection mechanism. ${ }^{[6]}$

\section{2 advantages and disadvantages of the ventilation pipe}

\section{advantage:}

1) Ventilation pipe is adapt to environmental performance, able to adapt to the permafrost of the external environment.

2) In the cold season, ventilation ducts can exert obvious cooling effect.

3) Buried in the subgrade embankment, which can effectively prevent the absorption of radiant heat transfer to the roadbed.

\section{Disadvantages:}

1) During the hot season, the convection of hot air is not conducive to the protection of frozen soil.

2) In addition to the impact of the Yin and Yang slope embankment, the ventilation pipe may lead to asymmetric temperature distribution of the roadbed.

\section{Conclusion}

Control measures for roadbed stability in permafrost regions are diverse, and each measure has its advantages and disadvantages, and we should develop its advantages and try to avoid its disadvantages. For the control measures to set the insulation layer, the effect of setting the insulation layer in the high temperature permafrost area is not conducive to the protection of frozen soil, so try to avoid setting the insulation layer in the high temperature permafrost area. For the control of buried hot rod, in order to make the influence of hot rod wider, the vertical layout can be changed to tilt or U-shaped. Taking into account the role of the yin and yang slope, the hot rod can be set uneven on both sides. ${ }^{[7]}$ For the ventilation pipe control measures, in order to make the cold air convect and the hot air does not produce convection, pipe cover can be added in the ventilation pipe nozzle with the cover can be controlled by the memory spring. If the temperature is low, the lid 
will open to convect the cold air. If the temperature is high, the lid will close to prevent the hot air degenerating the permafrost. In short, our aim is to control the temperature of roadbed, and can not increase the upper limit of permafrost so as to ensure the stability of roadbed.

\section{Acknowledgement}

This research was financially supported by the National Natural Science Foundation of China (Project Number: 211021130246)

\section{References}

[1] Dydyshko, P.I., Subgrade of High-Speed Railway on the Permafrost. Arctic, Subarctic: Mosaic, Contrast, Variability of the Cryosphere, ed. V.P. Melnikov and D.S. Drozdov. 2015. 113-116.

[2] Jin, L., et al., Cooling effect of thermosyhpon subgrade for Qinghai-Tibet Highway. Journal of Traffic and Transportation Engineering, 2016. 16(4): p. 45-58.

[3] Li, J.-p., et al., Evolution laws and failure characteristics of subgrade deformation in alpine permafrost region. Journal of Traffic and Transportation Engineering, 2016. 16(4): p. 78-87.

[4] Xie, S. and J. Qu, Effect of Sand Sediments Accumulated in Sand-control Projects on the Thermal Regime of Underlying Permafrost and Its Mechanism. Journal of the China Railway Society, 2013. 35(12): p. 77-82.

[5] Tang, T., et al., Simulation Analysis on Cooling Effectiveness of Engineer Measures for Subgrade of Qinghai-Tibet Expressway. Journal of Hunan University (Natural Sciences), 2016. 43(11): p. 95-102.

[6] Roadbed, embankment, tower support and culvert stability problems on permafrost. Sciences in Cold and Arid Regions, 2013. 5(4): p. 377-386.

[7] Feng, X. and Z. Liu, Discussion on Permafrost Hazards of Railway Engineering and Prevention Measures: A Case Study on Qinghai-Tibet Railway, in Advances in Chemical Engineering Ii, Pts 1-4, Z. Liu, F. Peng, and X. Liu, Editors. 2012. 